\title{
MATERIAIS COMO ALTERNATIVA PARA A GERAÇÃO DESCENTRALIZADA EM SISTEMAS SOLARES
}

Joyce Mara Brito Maia 11; Barbara Gomes Pereira 2²; Fábio André Lora $3^{2}$

${ }^{1}$ Universidade Federal do Recôncavo da Bahia, Centro de Ciência e Tecnologia em Energia e sustentabilidade; Feira de Santana/Bahia; joycemarabrito28@gmail.com 2 Universidade Federal do Recôncavo da Bahia, Centro de Ciência e Tecnologia em Energia e sustentabilidade; Feira de Santana/Bahia

Resumo: Podendo ser utilizada tanto para aquecimento quanto para geração de energia, a fonte solar é uma das energias renováveis mais discutidas e estudadas e em virtude disto, o objetivo deste trabalho é realizar uma revisão de literatura sobre materiais para confecção de coletores solares, que fazem uso da radiação solar para geração de energia. Além de discutindo brevemente sobre energia solar e geração distribuída. $O$ artigo em questão apresenta dados sobre materiais como o aço inoxidável, cobre e alumínio, ambos podendo ser utilizados para construção de peças de um coletor solar e nos conceitos e aplicações de geração distribuída.

Palavras-Chave: Energia solar; geração distribuída; coletor solar; materiais.

\section{ALTERNATIVE MATERIAL FOR DESCENTRALIZED GENERATION IN SOLAR SYSTEMS}

\begin{abstract}
Being able to be used as much as to gain energy, the solar source is one of the most discussed and studied renewable energies, because of this, the aim of this work is to conduct a literature review on materials for making solar collectors, which make use of from solar radiation to power generation. In addition to briefly discussing solar energy and distributed generation. This paper presents data on materials such as stainless steel, copper and aluminum, both of which can be used to construct parts of a solar collector and in distributed generation concepts and applications.
\end{abstract}

Keywords: Solar energy; distributed generation; solar collector; materials. 


\section{INTRODUÇÃO}

A vida cotidiana e a evolução humana é dependente direta da necessidade de energia, é com uso desta que realizamos a grande parte de nossas atividades diárias, desde acender uma luz para realizar uma simples leitura até utilizar um automóvel para realizar a própria locomoção para determinado destino. A energia utilizada pela sociedade vem de fontes que em conjunto formam a matriz energética, esta comumente é formada por fontes não renováveis e renováveis, sendo que a segunda tem ganhado espaço e desenvolvimento em pesquisa nas últimas décadas.

A falta de chuvas, avanço no desenvolvimento humano, elevada dependência de fontes hidráulicas e térmicas, aumento do consumo energético e fraco investimento em outras formas de geração de energia são fatores causadores de uma crise energética brasileira sofrida nos últimos anos [1].

O uso de fontes energéticas associadas a tecnologias elevou qualitativamente a vida humana, essa melhoria gerou como consequência um aumento no consumo energético, tornando fundamental a pesquisa e investimento em novas fontes de energia, principalmente as de cunho renovável. Como exemplo de fontes de energia temos os combustíveis fósseis, energia nuclear, energia hidrelétrica, biomassa, energia eólica e energia solar, alguns destes estão apresentados na Figura 01.

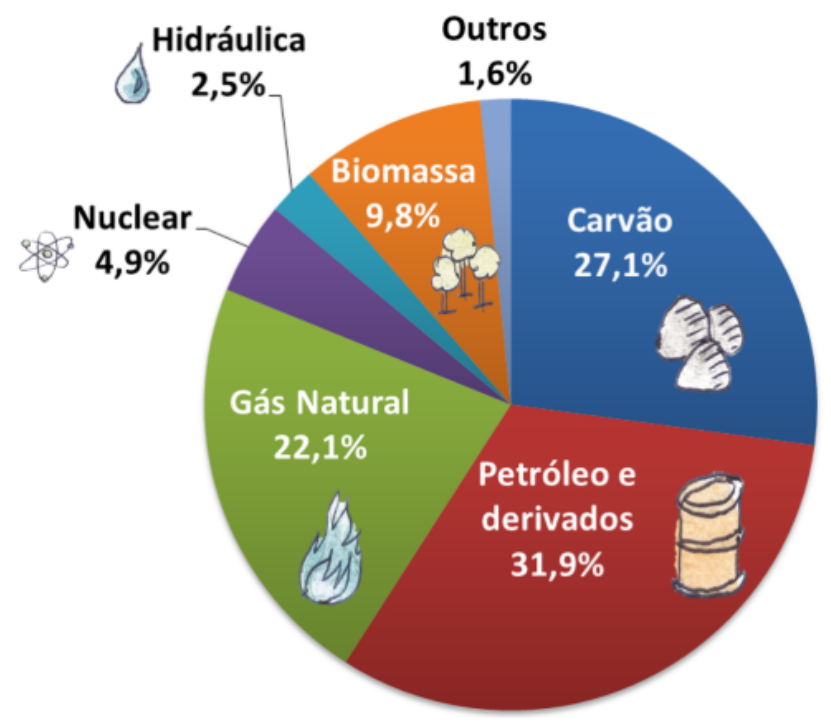

Figura 01 - Matriz Energética Mundial em 2016.

Fonte: IEA (2018, apud [2]).

Com os avanços do século $X X$, a geração de energia solar teve um grande desenvolvimento em tecnologia que vão desde o aquecimento de cilindros parabólicos para transformação de água em vapor dentro de receptores e funcionalidade de bombeamento até uso de placas solares para geração de energia elétrica.

O trabalho em questão tem o objetivo de apresentar uma revisão de literatura sobre materiais que podem ser utilizados para a construção de um coletor solar, abrangendo ainda assuntos como a geração de energia a partir de radiação solar e a 


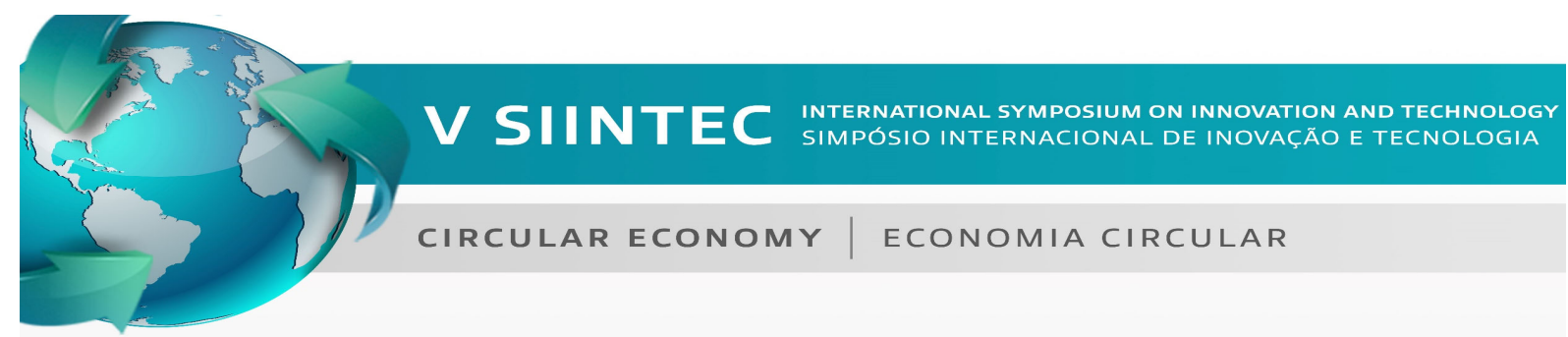

utilização de geração distribuída (geração de energia próximo da unidade que irá consumi-la e podendo ser oriunda de fontes fósseis ou renováveis), temas que estão ligados diretamente ao funcionamento dos coletores solares.

\section{METODOLOGIA}

Este artigo teve como objetivo realizar um estudo bibliográfico baseado em trabalhos com a temática da geração de energia de forma distribuída e com foco na energia solar, tratando ainda da utilização de coletores solares e seus possíveis materiais para confecção. Utilizando a classificação de acordo com o objetivo apresentado pode-se concluir que este é um estudo de cunho descritivo, já que se busca gerar maior familiaridade com o tema discutido para o tornar mais explícito ou criar hipóteses, possibilitando considerar vários aspectos relacionados ao fato estudado.

\subsection{Processo de geração de energia proveniente da radiação solar}

A energia solar é considerada uma fonte inesgotável que pode ser usada para geração de energia ou para aquecimento, este último muito usado desde o princípio das civilizações como forma de manter os alimentos preservados ou para secagem [1].

O sol disponibiliza uma elevada fração de potência na atmosfera da Terra de aproximadamente 174.000 TW, em termos práticos, 84 minutos de radiação solar seria suficiente para o consumo de energia elétrica mundial durante um ano [3].

Existem hoje duas formas de geração de energia através da utilização da energia solar, a fotovoltaica e a heliotérmica, a primeira consiste em obter de forma direta a energia elétrica a partir da solar quando a luz solar incidir sobre um material semicondutor e utilizar a radiação global como recurso. A heliotérmica consiste na radiação de incidindo em uma unidade coletora e transformada em energia elétrica, porém esta será discutida no próximo tópico.

Em decorrência das flutuações que ocorrem no clima, a radiação solar incidente na superfície da atmosfera sofre reflexões, dispersões e absorções até que esta chegue ao solo, sendo assim, a incidência total da radiação solar sobre um corpo situado no solo é somatório dos componentes direto, difuso e direto.

A radiação direta é a proveniente do disco solar de forma direta, sem que haja mudança de direção (desconsiderando a sofrida pela refração atmosférica), a radiação difusa se trata da recebida por um corpo após a modificação da direção sofrida pelos raios solares por causa do espalhamento e da reflexão, enquanto a radiação refletida é dependente da inclinação do equipamento e das características do solo [4].

\subsection{Geração distribuída}

A geração distribuída ocasionou na malha elétrica uma significativa mudança quando falamos em forma de geração de energia, este modelo traz uma geração feita 
em pequena escala conectada à rede e tecnologias consistentes em geradores e em alguns casos em fontes limpas de energia.

Na geração distribuída há de forma descentralizada um planejamento de geração e de despacho, isso faz com que não exista um órgão para comandar as ações de unidades de geração com estas [5]. Em resumo seria uma central com capacidade mínima para ter a possibilidade de conexão com a rede de distribuição e estar próxima ao consumidor.

O início da geração de energia no mundo se deu de forma distribuída, ocorrendo a geração de energia de forma isolada por parte de cada indivíduo que desejasse eletricidade. Porém devido ao aumento da busca por uso da eletricidade e necessidade de aumento da carga, os primeiros passos foram dados em direção a geração centralizada, já que a geração distribuída trabalha/limita-se a uma potência em torno de $30 \mathrm{MW}$. A geração descentralizada apresenta benefícios como o fornecimento de uma energia com custo muito reduzido, alto nível de segurança e a geração de menores danos ao meio ambiente quando se faz uma comparação com métodos comumente utilizados para a geração de energia.

Em países onde ocorre um crescimento expressivo da geração distribuída há incentivos ficais por parte do governo e alinhamento com regulamentação clara e atualizada para diminuir possíveis entraves da geração distribuída conectada à rede [6].

Em seu início os sistemas de geração distribuída foram utilizados como sistemas de emergência aumentando a independência do consumidor quando se falava em falhas do sistema elétrico, hoje em dia essas unidades são comumente abastecidas com diesel, porém se tem uma grande busca por sistemas de geração distribuída que utilizem fontes renováveis. Um exemplo que é possível citar é geração solar fotovoltaica que é conectada à um rede e acoplada a um sistema de baterias.

Um dos benefícios da geração distribuída é o desenvolvimento de uma rede inteligente capaz de monitorar e controlar estes sistemas quanto ao seu efeito sobre a performance do sistema elétrico principal, outro benefício principal é independência que o consumidor tem em relação a energia fornecida pela distribuidora e assim ele pode pagar o valor mínimo obrigatório, chamado de "Custo de Disponibilidade" [6].

\subsection{Materiais que podem ser utilizados para a construção de um coletor solar}

A utilização da energia por concentração solar implica em saber a forma correta de captação e armazenamento para obter uma boa eficiência de geração. Os coletores solares são equipamentos utilizados para realizar o aquecimento de fluidos, podendo ser líquidos ou gasosos, que podem ser coletores concentrados ou planos a depender da existência ou não de concentração de radiação solar [7].

O aspecto externo de um coletor solar plano é de uma caixa retangular coberta por vidro. Dentro da caixa há uma serpentina para o fluido escoar e em volta da serpentina existe uma superfície pintada de preto com o objetivo aumentar a absorção de calor pela placa, sendo esse transferido à serpentina e consequentemente o fluido 


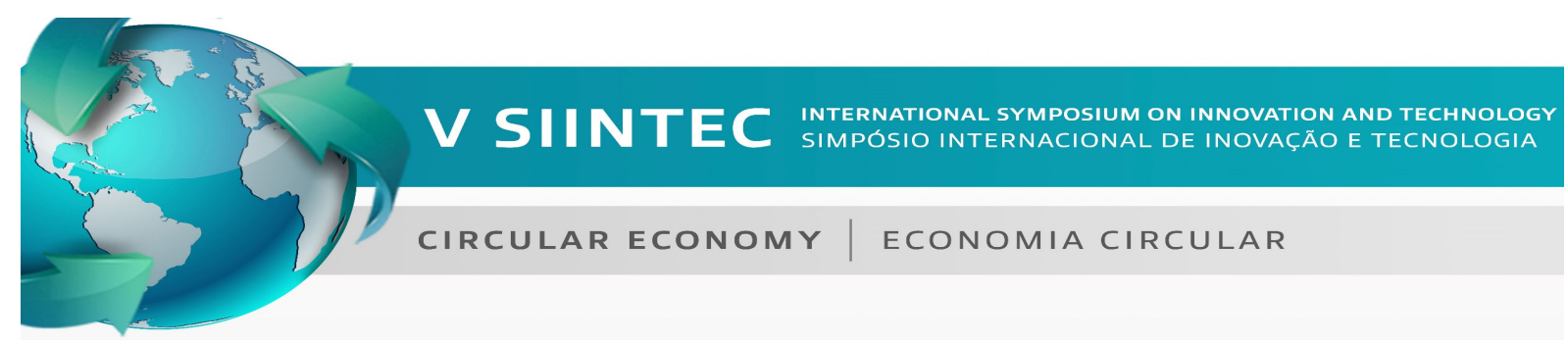

aquece ao passar pelos canos. Na parte inferior do coletor, com o objetivo de minimizar as perdas de calor é colocado um isolante térmico, enquanto a cobertura de vidro permite que a radiação solar entre e que o calor da placa se perca por convecção por causa da ação do vento. Existe ainda uma vedação que previne que a umidade entre no coletor, na Figura 02 são apresentadas algumas partes de um coletor solar plano.

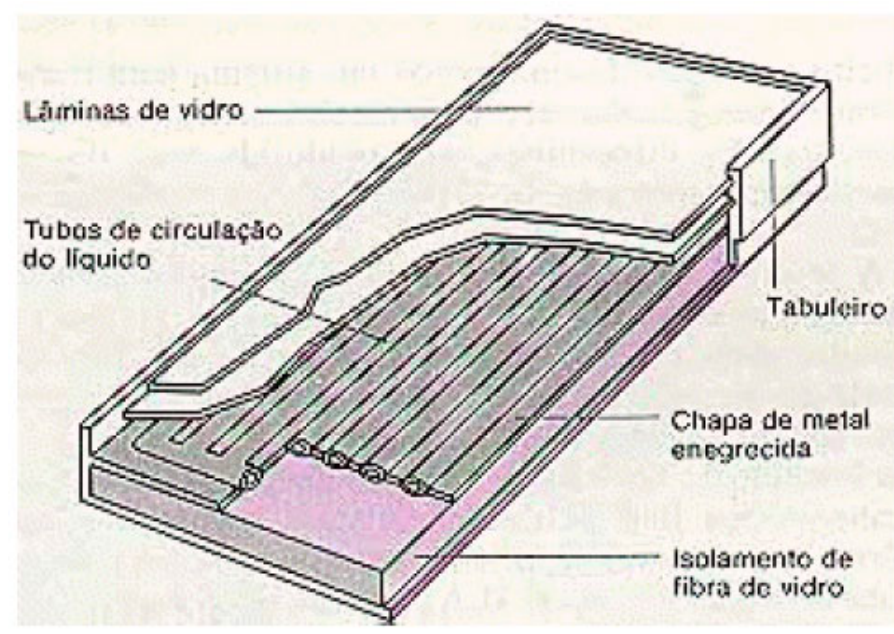

Figura 02 - Componentes de um coletor solar. Fonte: Souza (2000, apud [8]).

Nos coletores solares o fluido quando aquecido é mantido em reservatórios termicamente isolados até seu uso, podendo ser utilizado para aquecer água do banho, gerar ar quente para secagem de grãos, gerar gases para acionar turbinas, entre outras aplicações. Hoje em dia, os coletores solares planos são amplamente utilizados para aquecer água em residências, hospitais, entre outros, devido ao conforto e redução de consumo de energia elétrica [7].

Diante as alterativas de materiais existentes no mercado e que podem ser utilizados para a fabricação de um coletor solar é preciso se atentar a características como resposta ao possível congelamento da água, seu custo, variação dimensional do material, entre alguns outros fatores. Tradicionalmente se tem a utilização do cobre como material para a fabricação dos tubos dos coletores solares, sendo uma alternativa a utilização de aço inoxidável por apresentar maior tensão de escoamento [9]. A Figura 03 mostra um coletor que utiliza tubos de aço inoxidável com a cor preta para gerar uma baixa refletância.

O aço inoxidável garante à tubulação uma boa resistência à corrosão, uma grande resistência ao escoamento e resistência mecânica a tração, sendo estas características importantes para se evitar o rompimento dos tubos [8]. Quanto ao cobre utilizado em coletores muito se fala do tipo Cu DPL, um cobre com baixo teor de carbono, boa soldabilidade, boa resistência elétrica e boa condutividade térmica, sendo este um material que sempre esteve presente no desenvolvimento da humanidade. 

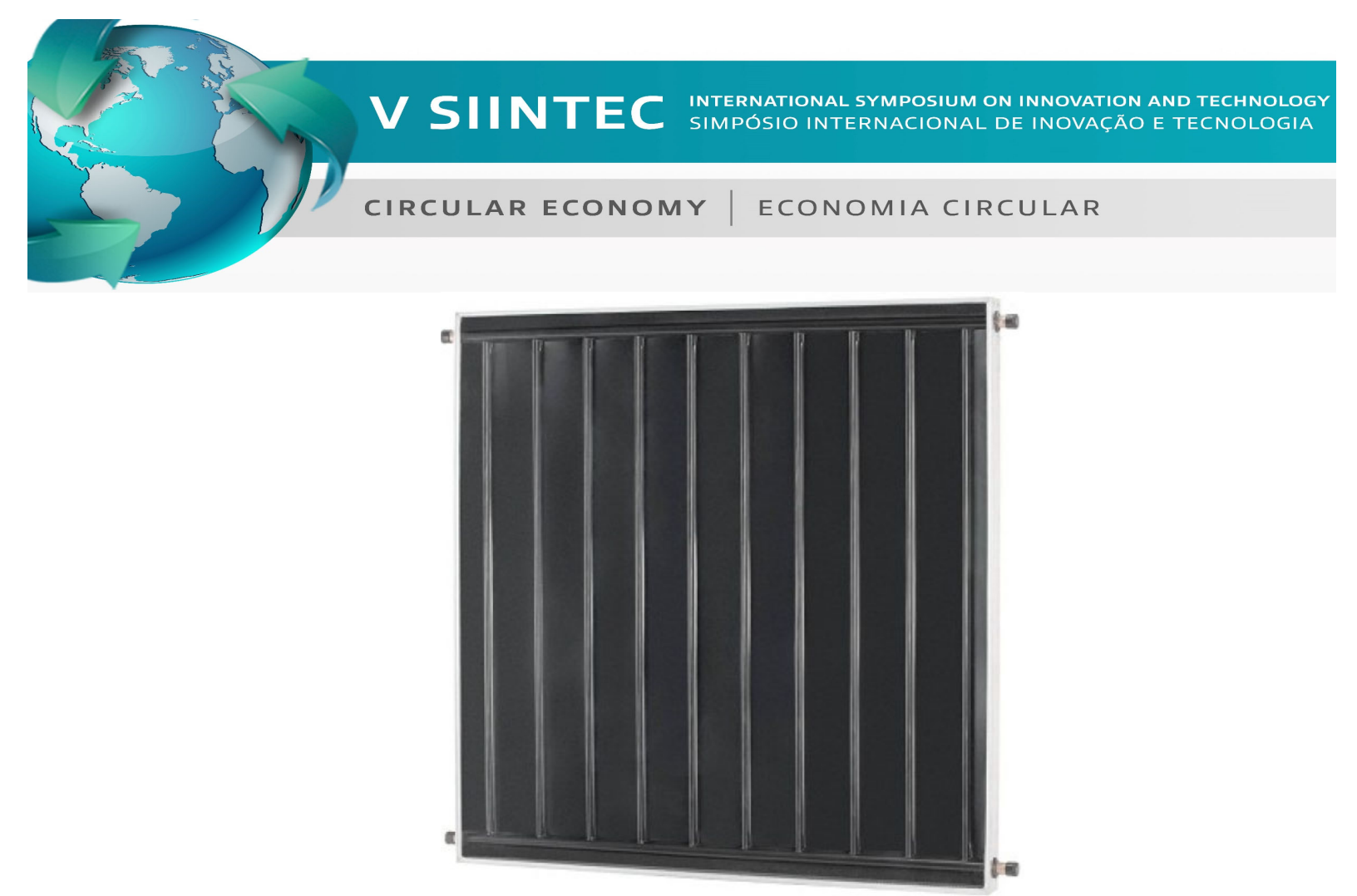

Figura 03 - Coletor com tubos em aço inoxidável.

Fonte: ENERGIAECO (2014, apud [9]).

Ao se falar em valores de condutividade térmica, o cobre apresenta resultado trinta vezes superior ao aço e quase duas vezes maior que o alumínio, sendo bastante indicado em aplicações como nos coletores solares, já que nestes sistemas não há necessidade de uma rápida transferência térmica. Algumas empresas estão adotando a utilização de ambos os materiais de forma acoplada, onde o aço inoxidável viria dentro do tubo de cobre e isso daria ao coletor uma maior resistência ao rompimento de seus tubos, sendo um sistema anticongelamento caso o uso do coletor seja em uma região que em determinadas épocas possa alcançar baixas temperaturas.

É possível fazer um comparativo de características entre o cobre e o aço inoxidável que sofre tratamento térmico, este último apresentando elevadas propriedades mecânicas, principalmente quando é observada a tensão de ruptura que no cobre é de 22 - $45 \mathrm{Kgf} / \mathrm{mm}^{2}$ enquanto a do aço é de $60-70 \mathrm{Kgf} / \mathrm{mm}^{2}$ e apresenta também valor muito mais elevado de limite de escoamento quando comparado com o cobre [9].

Apesar de o cobre apresentar boas propriedades, inclusive boa temperatura na saída do coletor, este material apresenta um custo elevado e isto acaba muitas vezes inviabilizando sua aplicação. É comum em coletores solares a utilização de alumínio para a fabricação da chapa absorvedora, material este que já chegou a ser oito vezes mais barato que o cobre, principalmente em função da sua abundância. O alumínio apresenta elevada resistência mecânica quando comparado com o cobre, ainda é um material bastante leve e de grande facilidade de transformação, um dos motivos de seu uso para a fabricação das chapas absorvedoras [10].

Possuindo uma condutibilidade térmica 4,5 vezes maior que a do aço, o alumínio apresenta uma excelente refletância devido ao alcance dos comprimentos de onda da energia radiante desde os raios ultravioletas, este material possui propriedades mecânicas avaliadas por meio de ensaios das amostras. Um coletor 
solar comumente apresenta tubulação de cobre, chapa absorvedora de alumínio, isolante térmico feito com lã de vidro e composição de vidro liso.

\section{CONCLUSÃO}

Os avanços da humanidade tornaram necessário realizar a conversão de um fonte de energia em outra e por muito tempo se focou em fontes não renováveis, fontes que prejudicavam de forma elevada o meio ambiente. A necessidade pela redução de taxas de emissões gerou um aumento nas pesquisas por fontes alternativas e limpas, entre essas podemos citar a energia solar, que teve alto incentivo em pesquisas e replicabilidade sendo bastante usada na forma de geração distribuída, já que é possível por exemplo instalar painéis solares em residências e reduzir o consumo da energia fornecida pelas distribuidoras.

O desenvolvimento do presente trabalho possibilitou a realização de uma pesquisa de cunho bibliográfico sobre geração distribuída e materiais possíveis de serem utilizados para a confecção de um sistema desde tipo, sendo colocado em foco o sistema por coletor solar plano.

Diante de todo o exposto no artigo, é possível compreender que a geração distribuída ocorre sem a centralização da geração e despacho da energia, sendo gerada pelo próprio consumidor e podendo ser obtida a partir de energia solar, como exemplo. Um dos sistemas que podem ser utilizados seria o de coletores solares, sendo abordados os possíveis materiais utilizados para sua fabricação, em que o alumínio aparece como o mais indicado por apresentar menor custo que os outros materiais citados e boas propriedades quanto ao funcionamento e eficiência do coletor.

\section{Agradecimentos}

Destinam-se os agradecimentos ao Conselho Nacional de Desenvolvimento Cientifico e Tecnológico - CNPq pelo fomento do projeto e bolsas de iniciação científica.

\section{REFERÊNCIAS}

1 CARVALHO, Cássio Cardoso de. FONTES HELIOTÉRMICAS: UM ESTUDO SOBRE O FUNCIONAMENTO E O POTENCIAL DE IMPLEMENTAÇÃO NO BRASIL. 2016. 55 f. TCC (Graduação) - Curso de Engenheiro Eletricista, Departamento Acadêmico de Eletrotécnica, Universidade Tecnológica Federal do Paraná, Curitiba, 2016.

2 IEA [International Energy Agency]. Matriz energética e elétrica. Disponível em: http://epe.gov.br/pt/abcdenergia/matriz-energetica-e-eletrica. Acesso em: 12 de agosto de 2019. 
${ }^{3}$ FILHO, C.,2014. "Metodologia para Estudo de Implantação de uma Usina Heliotérmica de Receptor Central no Brasil". UFRJ (Universidade Federal do Rio de Janeiro) - Rio de Janeiro - RJ - Brasil.

${ }^{4}$ REIS, Lineu Belico dos. Geração de energia elétrica. 2. ed. Barueri: Manole, 2011. 460 p. Revisada.

5 DRIEMEIER, Luís Henrique. Geração distribuída. 2009. 76 f. TCC (Graduação) Curso de Engenharia Elétrica, Universidade Federal do Rio Grande do Sul, Porto Alegre, 2009.

6 NARUTO, Denise Tieko. VANTAGENS E DESVANTAGENS DA GERAÇÃO DISTRIBUÍDA E ESTUDO DE CASO DE UM SISTEMA SOLAR FOTOVOLTAICO CONECTADO À REDE ELÉTRICA. 2017. 97 f. TCC (Graduação) - Curso de Engenharia Elétrica, Universidade Federal do Rio de Janeiro, Rio de Janeiro, 2017.

7 LOPEZ, Ricardo Aldabó. Energia solar para produção de eletricidade. São Paulo: Artliber, 2012. 229 p.

8 MACEDO NETO, Miguel Cabral de et al. APLICAÇÃO DE MATERIAIS ALTERNATIVOS PARA O USO DA ENERGIA SOLAR. Holos, [s.I.], v. 4, p.212-223, 4 ago. 2014. Instituto Federal de Educacao, Ciencia e Tecnologia do Rio Grande do Norte (IFRN). http://dx.doi.org/10.15628/holos.2014.663.

9 OlIVEIRA, Álvaro Daniel de. ANÁlise DE CUSTOS ENTRE COLETORES SOLARES QUANTO A ASPECTOS CONSTRUTIVOS. 2014. 37 f. Monografia (Especialização) - Curso de Especialista em Eficiência Energética Aplicada Aos Processos Produtivos, Universidade Federal de Santa Maria, Novo Hamburgo, 2014.

10 Associação Brasileira do Alumínio; Disponível em: <http://abal.org.br/aluminio/caracteristicas-quimicas-e-fisicas/propriedadesmecanicas/>. Acesso em 10 de agosto 2019. 